\title{
The development of communication skills through drama
}

\author{
Sarah Chatterton, \\ Speech and Language Therapist, Phoenix N.H.S. Trust \\ Sian Butler, \\ Drama Therapist, Phoenix N.H.S. Trust \\ Stoke Park, Stapleton, Bristol, BS16 1QU
}

Providing a Speech and Language therapy service to children with Severe Learning Difficulties (S.L.D.) offers much opportunity for multidisciplinary work. This summer I decided to take advantage of the links with Drama Therapy and run a short course of five weekly sessions for a group of seven children with the aim of developing communication skills through the use of drama. Five of the seven children had Down's syndrome and all were integrated into local mainstream schools.

The children were chosen according to their level of language ability. Although language levels differed, all could follow simple instructions and most conversational speech (being at levels 5-10 or above on the Derbyshire Language Scheme) and all were able to express themselves using short phrases and some connected speech. The children were aged between seven and 11 years. They were receiving 10 week blocks of therapy or were having their language skills reviewed on a termly basis. Although still benefiting from therapy input these children were not considered to be a high priority on the caseload and it was felt that the type of therapy that could be provided within the constraints of a mainstream school was not the most appropriate way to meet their communication needs.
Each group began with a 'warm up' activity which involved 'hello's', group gelling, finding out how everybody was feeling and discussing the proposed contents of the morning. If any particular issues arose during this time they were then followed through and incorporated into the activities. For example, when one child described a bad dream he had had the night before he was given the opportunity to act out the dream with the other group members. The situation was totally under his control and he was able to give the dream a happy ending. He appeared very proud to be in such a position of power and control. If no 'theme' was apparent then a scenario was suggested such as a trip in the jungle, or the building and protection of a castle. Other activities involved mime, imagination and creating individual stories or scenes around an object of each child's choice. Activities were both verbal and non-verbal. Although encouraged to be verbal and vocal there was no pressure for a child to speak at any time. One particular child preferred to act in silence while the therapist gave a running commentary of the scene in action. Much emphasis was given to the beginning and ending of each activity, session and the group as a whole. It was interesting to note that some of the children experienced difficulties with endings in particular.
It was agreed that the group leader would be the Drama Therapist, Sian Butler, and that my role would be to aid in the facilitation of the activities, to give appropriate language models and to promote and effective flow of communication. This framework was successful in that the children were not confused by there being two 'leaders' but there was the security of a familiar person being present. In addition, my detailed knowledge of the children, their background and their individual communication styles was invaluable for the smooth running of the group.

The groups were typically child centred and child led.

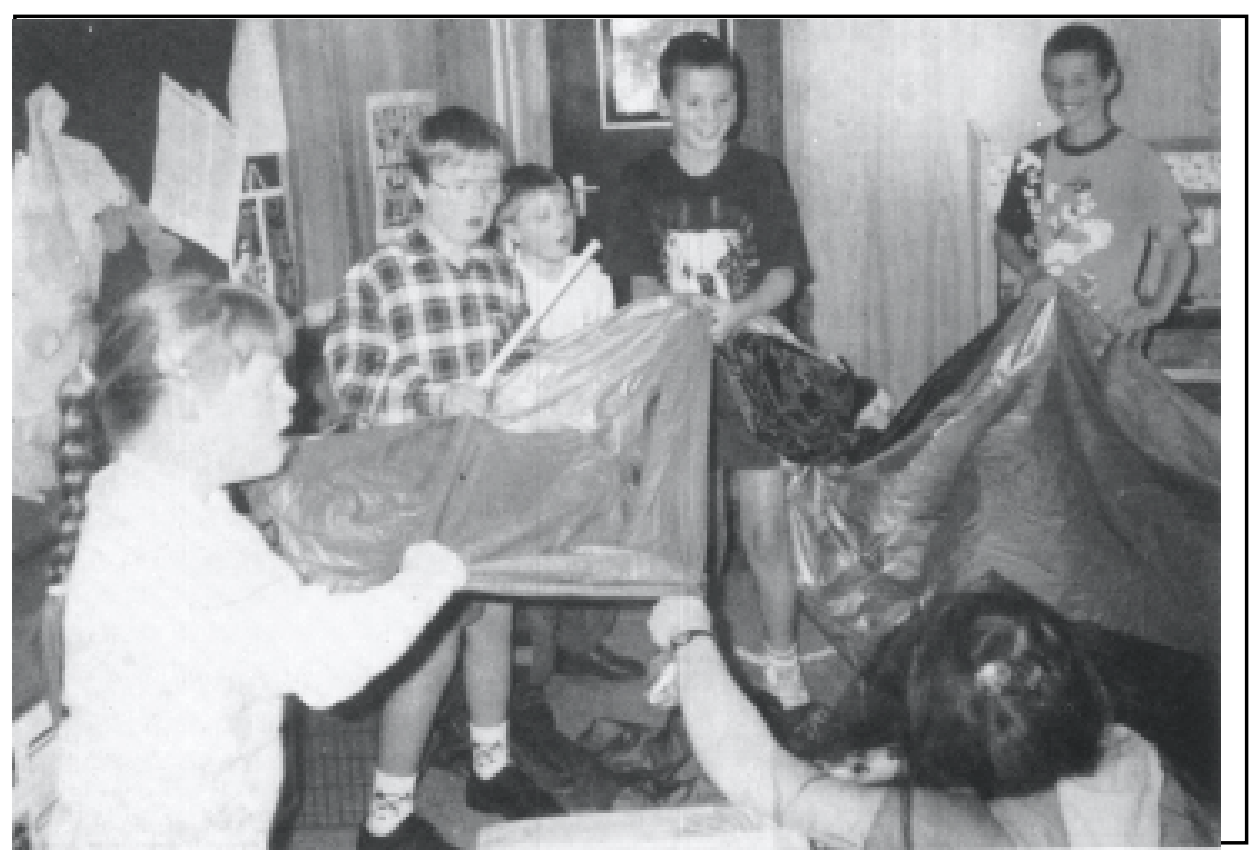

A group performance 
At all times the children were encouraged to use their imagination and own creativity. Opportunities arose for role play, mime, expression of own identity and how each individual viewed himself, teamwork and story generation. Linguistically there were opportunities for descriptive language, story telling, verbal prediction, giving directions, verbal negotiation, expression of feelings and emotions, use of abstract concepts and use of auditory and visual memory. Various 'props' were provided but these were deliberately abstract in nature such as lengths of different coloured and textured material, pieces of rope, balls of wool, stretchy material bags, tubes and circles of elastic. In this way the children could be creative with the props without being constrained by a predestined 'use'. Background instrumental music was played at times to enhance the atmosphere of an activity or scene.

There was a short break during each session for juice and biscuits and at this time the children tended to let off steam by dancing and doing various acrobatics. If a child did not want to join in any particular activity the decision was respected provided that child did not distract the rest of the group. Members of the group itself tended to keep each other 'on task' such that there was little need for the leader to intervene in times of dissent or lack of attention. Each session closed with a review of what had been done that morning and with a novel way of saying 'good-bye' such as rubbing noses Eskimo style or having a group hug.

The group was noted to gel and develop over the weeks and friendships between the children grew. The children became less reliant on the Speech and Language therapist as their 'security' and related more to each other than to the Drama Therapist. It was a sad session when it was time to say a final 'good-bye'. The enthusiasm of the children to attend the group each week was overwhelming with the exception of one boy whose attendance was erratic and so was not able to build up his confidence within the group. One particular child insisted on having an early night so that he could be bright and alert for the group each week.

In conclusion the running of the group was an invaluable experience for all concerned. The children were able to practise functional language skills and creative skills in a non-threatening and stimulating situation, away from the constraints of a set agenda, amongst peers of a similar ability. They were also able to express feelings and fears verbally and non verbally in a safe and confident environment. The Speech and Language Therapist observed the children communicating in a novel environment, worked with them in a group situation, took part in new activities which naturally lent themselves to the use of higher language skills, and learned from another skilled professional who had a different but complementary approach to working with children with S.L.D. The Drama Therapist had the opportunity to work with an age group with which she was not usually involved. As a result of the group, one referral was made for individual drama therapy input to enhance the child's self-esteem and confidence in communicating.

An additional advantage was that the group provided an opportunity for the parents to meet up and have an informal chat about their children on a weekly basis. This was considered to be invaluable as many parents express their sense of isolation if their child is the only one with special needs within a mainstream school. All the parents voiced a need for more groups of this nature to be run.

The running of the Drama/Communication Group appeared to be very rewarding, time effective and useful way of providing speech and language therapy within the school holidays. Hopefully there will be the opportunity to run more groups of this nature in future holiday periods and to evaluate the effectiveness of such an approach in a more objective manner.

\title{
Sleep disturbance in children with Down's syndrome
}

\author{
Wednesday 12 October
}

$10.00 \mathrm{am}-1.00 \mathrm{pm}$

\section{A half-day workshop at the Sarah Duffen Centre for parents and professionals}

\author{
led by Rebecca Stores
}

$£ 35.00$ for professionals, $£ 17.50$ for parents.

(a discount of $£ 5.00$ is available for members of the Portsmouth Down's Syndrome Trust.)

Please contact the Sarah Duffen Centre for application form. 